\title{
“OU TU É ZERO OU TU É DEZ”, ENTRE O SOFRIMENTO E O PRAZER: O CASO DOS GESTORES INTERMEDIÁRIOS DE UM BANCO
}

\author{
"Or you are zero or you are tem", between suffering and pleasure: the case of the intermediar \\ managers of a bank
}

" Ou vous êtes zéro ou vous êtes dix", entre plaisir et souffrance: le cas des cadres moyens d'une banque

“O tú es cero o tú es diez”, entre el sofrimento y el placer: el caso de los gestores intermediários de um banco

Elisangela Carpenedo de Mattos ${ }^{1}$ http://orcid.org/0000-0003-4421-1398

Mestra em Psicologia Social e Institucional pela UFRGS e doutoranda de Psicologia Social e Institucional na UFRGS. Graduada em Psicologia pela Faculdade da Serra Gaucha (2013). Integrante do Laboratório de Psicodinâmica do Trabalho da UFRGS. Universidade Federal do Rio Grande do Sul, Porto Alegre, Rio Grande do Sul, Brasil.

\section{Álvaro Roberto Crespo Merlo http://orcid.org/0000-0001-5016-0174}

Médico do Trabalho, Especialista em Saúde Pública pela Université Paris I (Panthéon-Sorbonne)em 1979, Doutor em Sociologia pela Université Paris VII (Denis Diderot) em 1996. Atua na área de Psicologia, com ênfase em Psicodinâmica e Clínica do Trabalho e na área da Medicina, com ênfase em Medicina do Trabalho. Líder do Grupo de Pesquisa Laboratório de Psicodinâmica do Trabalho da UFRGS. Universidade Federal do Rio Grande do Sul, Porto Alegre, Rio Grande do Sul, Brasil.

Jaqueline Perozzo Andreazza3 http://orcid.org/0000-0001-5684-1384

Graduação em Psicologia pela Universidade de Caxias do Sul (1990). Especialista em Administração de

Recursos Humanos (UCS). Curso de Aperfeiçoamento em Human Resources Management (Broward Community College - USA). Mestre em Psicologia Social e Institucional da UFRGS (2006 - 2008). Psicóloga Clínica, Consultora em Gestão de Pessoas. Psicanalista. Caxias do Sul, Rio Grande do Sul, Brasil.

\section{Resumo}

Este artigo tem por objetivo analisar a dinâmica prazer-sofrimento no trabalho bancário de ocupantes de cargo de gestão intermediária, em um banco estatal, em diversas agências localizadas no Estado do Rio Grande do Sul. Nele apresentamos os resultados parciais de uma pesquis a qualitativa, utilizando como instrumento entrevistas semiestruturadas e analisadas à luz da Psicodinâmica do Trabalho. Dos achados encontrados, nossos estudos

1 eliscm27@gmail.com

2 merlo@ufrgs.br

3 Jaqueline.andreazza@gmail.com 
apontaram fatores relacionados a vivências de prazer: a satisfação em resolver os problemas dos clientes; vivências de sofrimento: a excessiva cobrança de metas, consideradas inatingíveis, intensificado pela existência de avaliações individuais objetivas, que desconsideram s esforço empregado para realizar uma tarefa, causando frustração, bem como, o volume de serviço excessivo e o sofrimento ético, todas estas podendo culminar no adoecimento do trabalhador; assim como os identificados ora como fontes de sofrimento, ora como de prazer: o reconhecimento, a sensação de estabilidade e a quantofrenia.

Palavras-chave: Psicodinâmica do Trabalho; Prazer e sofrimento; Bancários; Gestores interemediários.

\begin{abstract}
The purpose of this article is to analyze the dynamic pleasure-suffering in the banking work of intermediate management occupants in a state bank, in several agencies located in the State of Rio Grande do Sul. We present the partial results of a qualitative research using as instrument semi-structured interviews and analyzed in the light of Work Psychodynamics. Of the findings found, our studies pointed to factors related to pleasure experiences related to satisfaction in solving clients' problems; experiences of suffering, related to excessive collection of goals, considered unattainable, intensified by the existence of individual objective evaluations, which disregard effort to perform a task, causing frustration, as well as excessive service volume and ethical suffering, all of which can culminate in the sickness of the worker; as well as those identified as sources of suffering, sometimes as sources of pleasure: recognition, the sense of stability, and the quandary.
\end{abstract}

Keywords: Work Psychodynamics. Pleasure and Suffering. Bankers. Intermediary Managers.

\title{
Résumé
}

Cet article vise à analyser le plaisir souffrance dynamique dans la position de travail bancaire des occupants de cadres intermédiaires dans une banque d'État dans plusieurs succursales situées dans l'État de Rio Grande do Sul. Nous y présentons les résultats partiels d'une recherche qualitative, en utilisant comme des entretiens semistructurés instrument et analysés à la lumière de la psychodynamique du travail. Parmi les résultats trouvés, nos études ont mis en évidence des facteurs liés aux expériences de plaisir liées à la satisfaction de résoudre les problèmes des clients; expériences de souffrances, liées à des objectifs de collecte excessive, considérée comme inaccessible, intensifié par l'existence d'une évaluation individuelle objective, effort de mépris employé pour accomplir une tâche, ce qui provoque la frustration, ainsi que le volume du service excessif et la souffrance éthique, tout cela peut culminer dans la maladie du travailleur; ainsi que ceux identifiés ici comme source de souffrance, parfois plaisir: la reconnaissance, le sens de la stabilité et quantofrenia.

Mots-clés: Psychodynamique du travail. Plaisir et souffrance. Banquiers Directeurs intermédiaires.

\section{Resumen}

Este artículo tiene por objetivo analizar la dinámica placer-sufrimiento en el trabajo bancario de ocupantes de cargo de gestión intermedia, en un banco estatal, en diversas agencias ubicadas en el Estado de Rio Grande do Sul. En él presentamos los resultados parciales de una investigación cualitativa, utilizando como instrumento entrevistas semiestructuradas y analizadas a la luz de la Psicodinámica del Trabajo. De los hallazgos encontrados, nuestros estudios apuntaron factores relacionados a vivencias de placer, relacionadas a la satisfacción en resolver los problemas de los clientes; y en el caso de las mujeres, de las mujeres, de las mujeres, de las mujeres, de las mujeres, de las mujeres. culminar en la enfermedad del trabajador, así como los identificados como fuentes de sufrimiento, como de placer: el reconocimiento, la sensación de estabilidad y la cuántofrenia.

Palabras clave: Psicodinámica del trabajo. Placer y sufrimiento. Bancario. Gestores Intermedios.

INTRODUÇÃO

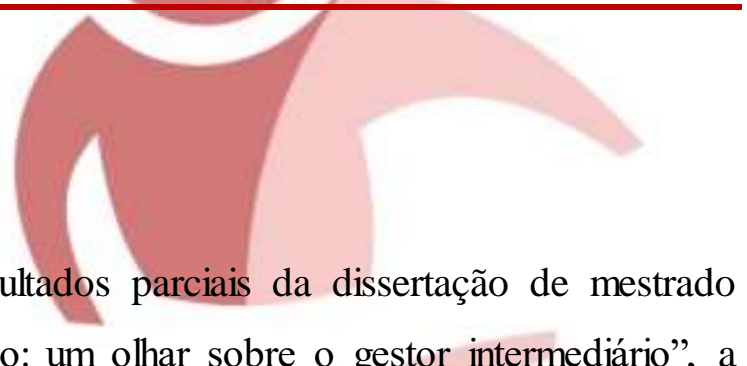

intitulada "Prazer e sofrimento no trabalho bancário: um olhar sobre o gestor intermediário", a 
qual teve como principal objetivo analisar a dinâmica prazer-sofrimento no trabalho de bancários que ocupavam cargo de gestão intermediária em um banco estatal. Para isso, foram realizadas entrevistas com os trabalhadores, em agências localizadas em duas diferentes cidades do interior do estado do Rio Grande do Sul. Sendo o objetivo específico deste trabalho, elencar e analisar as vivências de prazer e sofrimento manifestas pelos trabalhadores entrevistados.

Optamos pela pesquisa com gestores intermediários, devido aos parcos estudos publicados, no intuito de compreender a dinâmica prazer-sofrimento no trabalho (Aguiar, 2013). Além disso, pesquisas de Dejours (1989) apontaram que a gerência média fica no chamado nível executivo intermediário, sendo com frequência alvo prioritário em caso de conflito, produzindo sofrimento. Ademais, por fazerem a ligação entre o "chão de fábrica" e os escalões superiores, frequentemente são vítimas da desconfiança e tática do segredo por parte dos subordinados, além de obrigados a suportar as pressões geradas pelos altos executivos e direção da empresa.

Consideramos importantes os estudos relacionados ao trabalho e a relação desses com o trabalhador, tendo em vista as profundas modificações ocorridas nesse cenário, sobretudo nos últimos cem anos e que foram intensificadas a partir dos anos 1980, uma vez que têm consequências para a saúde do trabalhador. Tal processo se inicia com a Revolução Industrial, ocorrida no século XVIII, na qual o trabalho artesanal entrou em declínio, dando lugar à produção mecanicista, que de acordo com Decca (1996) tinha por objetivo a disciplinarização e a hierarquização na produção, a vigilância, ou em outras palavras, uma diversidade de formas de controle. O Taylorismo, a partir do final do século XIX, busca propiciar maior produtividade no trabalho, evitar o desperdício, economizar mão-de-obra por meio da racionalização da produção, intensificando o trabalho (Castel, 1998). E logo após o Fordismo, em meados de 1913, que é entendido como um modo de produção pautado em inovações técnicas e organizacionais, que visam a produção e o consumo massificados (Guimarães, 2006). Separa-se a concepção da execução, e ao operário, resta somente a execução, sendo a responsabilidade pelo pensar conferida a outros.

$\mathrm{Na}$ esteira dos modelos de gestão, surge o Modelo Japonês ou Toyotismo, o qual traduz o processo de reestruturação produtiva, em eclosão, caracterizando-se pela produção conforme demanda; trabalho em equipe; processo produtivo flexível; horizontalização do trabalho e descentralização das decisões; gestão conjunta; terceirizações, além dos CCQ's4,

${ }^{4}$ CCQ’s - Círculos de Controle de Qualidade 
(Antunes, 2002). Os modelos de gestão descritos, amalgamados nas empresas brasileiras contemporâneas, estão pautados no ideário neoliberal, sacrificam a subjetividade em prol da rentabilidade e competitividade, por meio dos já citados trabalho flexível, terceirizações, horizontalização e na gestão conjunta, resultando em funcionários mais aderentes às políticas da empresa (Merlo, 2000), decorrendo disso seu mal estar e nosso interesse pela pesquisa.

\section{MATERIAIS E MÉTODOS}

No intuito de atingir os objetivos propostos, empreendemos uma pesquisa qualitativa de campo. Conforme Heloani e Lancman (2004), a abordagem qualitativa parece ser a mais adequada, quando se procura compreender um fenômeno na sua totalidade. É um método que se propõe a esclarecer os motivos de determinados fenômenos, aprofundando sua compreensão sem quantificá-los, pois não se tratam de dados mensuráveis, mas resultam da interação entre os sujeitos (Silveira \& Córdova, 2009). A pesquisa de campo, segundo Cruz (2002), possibilita a aproximação daquilo que queremos conhecer e estudar, além de produzir conhecimento a partir do que é encontrado no campo.

Como instrumento de pesquisa, utilizamos as entrevistas semiestruturadas, a fim de investigar as vivências de prazer e sofrimento no trabalho desses sujeitos. Tal instrumento nos permite tanto a coleta sistemática dos dados, sua análise e descrição, assim como maior flexibilidade, pois apesar de existirem questões norteadoras, os tópicos são desenvolvidos a partir da interação pesquisador/entrevistado (Breakwell et. al., 2010). Por fim, procedemos ao exame minucioso dos resultados apoiados nos pressupostos da Psicodinâmica do Trabalho, para a qual, conforme Dejours (2004), não interessa a objetividade, mas a versão dos trabalhadores acerca dos fatos.

Os sujeitos desta pesquisa foram 16 bancários, ocupantes de cargo de gestão intermediária. Destes, oito são do sexo masculino e oito do sexo feminino, todos com carga horária semanal formal de 40 horas. A idade dos mesmos variou de 29 a 52 anos. Quanto à educação formal, dez deles eram pós-graduados à época da pesquisa, um estava cursando MBA, quatro eram graduados e um possuía curso técnico. Em relação ao tempo como bancários, os mesmos estavam de seis a 27 anos no banco, sendo que desses, apenas um trabalhou em outra instituição financeira, antes de trabalhar no banco pesquisado. Quanto ao tempo como gestor, estavam entre oito meses e 20 anos de cargo. Destes, um dos gestores já havia ocupado cargo análogo em outra instituição financeira. 


\section{RESULTADOS E DISCUSSÃO}

A partir dos comentários verbais emitidos pelos trabalhadores, foram construídos três eixos temáticos, que constam na íntegra na dissertação já citada, dos quais citaremos e descreveremos apenas o primeiro. Este que é relativo às Vivências de Prazer e Sofrimento no Trabalho e que foi subdividido nos seis subeixos citados a seguir: reconhecimento, sensação de estabilidade, pressão por metas, sobrecarga de trabalho e sofrimento ético, a quantofrenia e o adoecimento no trabalho.

No tocante às vivências de prazer e sofrimento no trabalho, inicialmente é preciso esclarecer esses conceitos, visto serem inerentes à atividade de trabalho (Dejours, 2004a), não devendo ser compreendidos como excludentes. O prazer é concebido como aquilo que é mobilizado pelo sujeito a fim de obter gratificação, realização pessoal e reconhecimento. É viabilizado pela sensibilização de sua inteligência prática, frente aos constrangimentos da organização do trabalho, no intuito de provocar a ressignificação do sofrimento (Dejours, 1993). O sofrimento, por sua vez, constitui-se em um processo que é iniciado quando a organização é rigidamente organizada, não sendo possível nenhuma adaptação do trabalho à personalidade do trabalhador (Dejours, 1993), impedindo a realização pessoal e, portanto, a satisfação no trabalho.

Percebemos em nossa pesquisa que as mesmas categorias são, por vezes, fontes de prazer e/ou satisfação no trabalho, e outras são fontes de sofrimento. Para Resende (2003), isso ocorre pelo caráter dialético da dinâmica prazer-sofrimento, vista a possibilidade de ambas vivências coexistirem simultaneamente, marcando o movimento de luta do trabalhador pela busca da satisfação e evitação do sofrimento, com o propósito de se manter psiquicamente equilibrado. Nas linhas que seguem, descreveremos os subeixos, associados aos comentários verbais e a análise por nós empreendida. Destacamos que tal divisão é meramente didática, vistos os entrelaçamentos dos eixos abordados.

\section{Reconhecimento}

Em relação ao subeixo reconhecimento, temos que este é compreendido pela Psicodinâmica do Trabalho como a retribuição simbólica recebida pelo trabalhador, decorrente da contribuição do mesmo à empresa na qual trabalha, estendendo-se a toda sociedade. Ressaltamos se tratar de uma retribuição simbólica ou moral, não dizendo respeito a salários, bônus ou promoções (Dejours \& Bègue, 2010). A contribuição oferecida pelo 
trabalhador busca dar sentido para si, ao trabalho que realiza, e contribui para a constituição de sua identidade (Dejours, 1993; Gernet \& Dejours, 2011).

O reconhecimento se dá por meio do julgamento do trabalho realizado, o qual passa por duas provas: o julgamento de utilidade e o julgamento de beleza (Dejours, 1993; Dejours, 2005; Dejours \& Bègue, 2010; Gernet \& Dejours, 2011). O julgamento de utilidade é relativo à contribuição econômica, técnica ou social do assalariado para a empresa. Concerne não somente à qualidade do trabalho, da engenhosidade que o trabalhador teve que lançar mão, mas aos riscos que correu para atingir os objetivos. É enunciado principalmente pela hierarquia e mais raramente pelos subordinados, assim como, os clientes, tendo em vista as atuais formas de gestão (Dejours, 2005; Gernet \& Dejours, 2011). Conforme segue:

$\mathrm{Na}$ realidade é conversa mesmo. É muitas vezes a gente pegar e conversar com nosso gestor [...] ele dizer isso tá bem, isso tá legal, nisso eu vejo que os clientes te elogiam sobre isso, aquilo, aquilo.

O reconhecimento no trabalho, também advém da resolução de problemas, manifesto pelos bancários ao referirem satisfação ao solucionar demandas trazidos pelos clientes. Isso, porque o cliente se beneficia da habilidade do trabalhador, quando da resolução dos seus problemas, e esse, por sua vez, vivencia o prazer proveniente do reconhecimento. Achados de Santos (2013) sobre a satisfação derivada dessa relação com o cliente, demonstram que a mesma oportuniza dar sentido ao trabalho, pois permite ao bancário perceber o valor do seu trabalho.

Eu gosto muito quando o cliente chega com algum problema, me sinto bem em poder resolver, em poder ajudar que eu vejo que a pessoa sai satisfeita. É muito bom tu muitas vezes negociar com algum cliente alguma coisa que tu sabe que é uma coisa que ele precisa [...] e ele sai bah que bom que tu me ofereceu né, que bom era uma coisa que eu queria fazer mesmo.

Com referência ao segundo julgamento, o de beleza, em acordo com Dejours (1993), Dejours (2005), Dejours e Bègue (2010), Gernet e Dejours (2011), esse diz da compatibilidade do trabalho executado, em relação às regras da arte e de ofício. É o trabalho bem feito, que só pode ser julgado pelos pares, aqueles que conhecem o ofício, assim como quem o realizou. É mais preciso, sutil e severo. Mas não diz de um julgamento sobre o sujeito, é sobre o seu fazer. Atesta a originalidade do autor, em relação aos seus colegas, por isto essencial para afirmação da identidade no trabalho, distinguindo o trabalhador de seus pares, e de reconhecimento em reconhecimento, aquela se fortalece (Dejours \& Bègue; 2010). $\mathrm{O}$ julgamento de beleza aparece no relato a seguir, em que o trabalhador concorre para uma 
vaga para ser promovido, na própria agência em que trabalha, e é apoiado pelos colegas, que por reconhecerem seu trabalho, acreditam que ele merece a vaga.

Eu "tava" concorrendo porque, "tava" habilitado e tal. [...] E eu senti a sinceridade do pessoal, [...] foram vários. E o pessoal "não, nós estamos torcendo por ti, nós queremos que tu fique". [...] Mas isso é importante, é o reconhecimento do teu colega. Então, se tem esse reconhecimento dele, é bom pra ti.

Ressaltamos, porém, que o reconhecimento verbalizado tem caráter efềmero, visto existir, mas não com base suficientemente sólida, que nos permita afirmar que a dinâmica do reconhecimento efetivamente acontece. Pois, alguns entrevistados, quando questionados, relacionaram o reconhecimento no trabalho à promoção ou à remuneração, conforme seguem:

Graças à Deus, sempre que surgiram as oportunidades, que eu me coloquei à disposição, sempre consegui atingirmeus objetivos, chegar aonde eu queria chegar. [...] Então, vem o reconhecimento, tanto na forma de promoção, como também vem reconhecimento do, tanto de gestores, quanto dos próprios clientes.

Sim. A princípio sim, em termos de, o maior reconhecimento do banco comigo seria remuneração".

Embora a remuneração possa funcionar como forma de reconhecimento, além de prover os meios materiais para a sobrevivência e consumo, como mencionado no trabalho de Perez (2012), com professores universitários da rede privada, destacamos que não é a remuneração que mantém as pessoas trabalhando. Como ratificado a seguir: Só que realmente o que me motiva é conseguir, assim, obter o resultado. Acho que
isso pra mim é o meu maior ganho. Semestre passado, quando eu consegui fazer
$106 \%$ da meta [...] que foi parar na página da Superintendência, quando eu vi
aquilo assim, aquilo não tem salário, não tem dinheiro nenhum que pague, sabe. É o
resultado do teu trabalho[...].

Causam preocupação os danos que, porventura, possam ocorrer ao atrelar reconhecimento à ascensão profissional. Isso porque, conforme Nardi (2006), as políticas neoliberais preconizam uma taxa "natural" de desemprego ou o chamado desemprego estrutural, de acordo com Alliez e Feher (1988), Antunes (2002), Barreto e Heloani (2014). $\mathrm{Na}$ mesma lógica, é possível pensar que, apesar de os trabalhadores possuírem as competências para ocupar cargos hierarquicamente superiores, o número de vagas disponíveis é inversamente proporcional conforme se sobe na hierarquia, não sendo possível atender a todos que almejam ocupá-los. Logo, dependendo da forma como os processos seletivos são conduzidos e concluídos, a frustração em relação a si e o sentimento de incompetência podem emergir, a autoculpabilização pode ocorrer, juntamente com a sensação de falta de 
reconhecimento, como demonstra a fala desta trabalhadora que aspira ascender na carreira e não consegue.

\begin{abstract}
Não, sinceramente não. [...] Reconhecimento pra mim, é tu mostrar que tu realmente é capaz. Agora tu ser capaz, e tu nunca poder mudar, sendo que tu quer mudar, pra mim isso não é reconhecimento.
\end{abstract}

Deve-se atentar para a supressão do reconhecimento, a qual indica que o local de trabalho impede que este seja convertido em prazer e o sofrimento, ressignificado, por não conceder as condições básicas para isso (Perez, 2012). Nossos sujeitos de pesquisa, inicialmente verbalizaram realização profissional e sentimentos de reconhecimento, mas com a evolução de suas falas, torna-se visível a falta de reconhecimento advinda da organização.

O reconhecimento no banco é muito subjetivo, é muito subjetivo. [...] E eu acho que o banco peca nisso também, ações de reconhecimento. [...] Acho que não me sinto valorizada, não. Ainda mais assim, se tu fez, tu fez aquilo que foi pedido, tu fez a tua obrigação. E se tu não fez, tu não presta. Então, acho que não me sinto valorizada pela instituição.

Sendo assim, ao ser privado do reconhecimento em seu trabalho e, consequentemente, do sentido deste, o sujeito se vê imerso unicamente em sofrimento, podendo culminar com a doença mental (Dejours, 2007). Dessa forma, entende-se que não há neutralidade no trabalho, sempre haverá uma produção, quer seja no âmbito da saúde, quer da doença (Dejours, 2001; Dejours, 2007; Dejours \& Mello, 2012).

\title{
Sensação de Estabilidade
}

Diante do contexto capitalista contemporâneo, sobretudo no que concerne à desregulamentação das relações de trabalho, a qual é manifesta e regulamentada em nosso país na atualidade, Nardi (2006) já ressaltava que essas inviabilizavam o pleno emprego. Em complementação, temos que, o ideário neoliberal é pautado no restabelecimento de uma taxa "natural" de desemprego, conforme anteriormente citado, fundamental segundo eles, para o incentivo à competitividade. Ademais, a concorrência decorrente da transnacionalização do capital, um dos fatores que favorecem a nova segmentação da força de trabalho, contribuem para o aumento do desemprego estrutural (Alliez, Feher, 1988; Antunes, 2002). À vista disso, temos que diante do desemprego estrutural e escassez de oportunidades, o trabalhador submete-se incondicionalmente às regras corporativas, experienciando o medo $\mathrm{e} a$ insegurança (Aguiar, 2013). 
Sendo assim, nesse cenário de restrição de postos de trabalho e disseminação da ideologia do medo, não nos surpreende a maioria dos entrevistados ter referido que optou pelo concurso, por conta da estabilidade. Contudo, no caso deles, essa escolha é ilusória, pois são empregados públicos e estão submetidos às mesmas regras de demissão que empregados de empresas privadas. Desta forma, possuem na realidade segurança, que é diferente de estabilidade. Entretanto, sua percepção é diferente:

Eu trabalhava em uma empresa que eu comecei a trabalhar lá no ano 2000, fazia 4 ou 5 anos que eu trabalhava lá e aí uma sexta-feira, no final da tarde, o chefe me chamou na sala dele, às 5 h30min da tarde para me dizer que "tava" rescindindo meu contrato. Daquele dia em diante, eu passei a pensar em sair da iniciativa privada, fazer algum concurso.

Assim como em estudos realizados por Resende e Mendes (2004), nos parece que a segurança oportunizada para si e para a família é determinante para a permanência na instituição, em detrimento dos sentimentos de auto realização. Grisci, Scalco e Kruter (2011) encontram algo semelhante em seus estudos, apontando que a entrada em instituições bancárias decorre, sobretudo, da necessidade, constituindo-se em um meio de sustento, diferentemente do status anteriormente conferido aos bancários. Isto leva o trabalhador a viver um dilema pessoal, ao refletir que sua decisão anterior o levou à uma vida não satisfatória, porém não mais passível de renúncia.

A gente tem que dar o resultado de um banco privado, mas a gente tem uma certa segurança que num banco privado, segurança de não perder o emprego, de não ser demitido, que num banco privado talvez não exista. Então, eu acho que isso nos escraviza um pouco. A gente fica escravo daquilo que a gente tem a perder. Porque a gente passa por momentos complicados, que talvez se tu tivesse numa empresa privada, talvez tu fosse repensar: "não sei se tá valendo à pena, daqui há pouco...".

Percebemos então que o medo do desemprego em associação com a falsa sensação de estabilidade no banco pesquisado, aliados ao receio de não conseguirem colocação melhor no mercado de trabalho, com salário tão atraente, faz com que, mesmo diante do sofrimento e da doença, os trabalhadores continuem trabalhando.

[...] se eu não tivesse a estabilidade, eu já teria saído da empresa. [...] eu já teria abandonado, [...]. Não estaria aí sofrendo como tem muita gente que eu vejo. 


\section{Pressão por Metas}

As metas no trabalho bancário contemporâneo, ocupam posição central, visto dizerem muito do que é ser bancário, além de ser fonte de reconhecimento. Em nossa pesquisa, aquelas aparecem de maneira ambígua, ora ocasionando sofrimento, por conta da impossibilidade de atingi-las; ora como fonte de prazer, quando são reconhecidos, ao atingir os objetivos propostos pela instituição. As queixas acerca do aumento da pressão para atingirem as metas são referidas principalmente por aqueles com mais de 10 anos de serviço, mas não relacionando à meta em si, mas a forma de cobrança da mesma. Do ponto de vista dos trabalhadores, o banco pesquisado desconsidera o contexto econômico, quando da definição das metas, conforme comentários:

É aquela coisa, a crise começou pra todos, menos pro banco.

E vem a cobrança, vem, não querem nem saber. De cinco em cinco minutos "tão" lá: “conseguiu o que? fez o que?"... a pressão é muito grande.

Ademais, a sensação desses bancários é de que os objetivos definidos, são definidos sempre em um patamar impossível de cumprir, muito disso pois, na instituição pesquisada, as metas são definidas, e os trabalhadores avaliados conforme o desempenho apresentado, considerando os indicadores pré-estabelecidos.

A meta é sempre em excesso. Eu acho que eles, quem faz o orçamento já pensa, eu vou jogar a meta tantos por cento acima, se tiver um louco que fizer já é lucro. [...] Que assim, no último semestre, todo mundo sabe que o país tá em crise e tal, que a gente tá vivendo uma recessão, e a meta, todas elas, vieram com ajuste. Todo mundo tá em crise, menos o cliente do banco pesquisado. [...] Então, é óbvio que tu olha...tu quer atingir, óbvio que a minha ideia é sempre chegar, mas tu olha pra ela e diz assim: "meu Deus de onde eu vou tirar? De onde eu vou tirar?", porque as pessoas estão correndo do banco. Então. E isso que é ruim, é ver, é ter essa sensação de que a meta é inatingível.

Conforme relato de uma trabalhadora, com acesso a níveis estratégicos do banco estudado, os analistas definem as metas sabendo que elas provavelmente não serão alcançadas, considerando o contexto econômico. O objetivo é que as agências cheguem o mais próximo possível do número estipulado, não de que o número seja cumprido. Entretanto, a imensa maioria dos trabalhadores desconhece essa lógica, efetuando intensa mobilização para se chegar num patamar já sabido que não será possível chegar. Entendemos que, dessa forma, na melhor das hipóteses, o bancário trabalha desmotivado, além de reforçar nele sentimentos de menos-valia, impotência e incompetência, por não chegar aos objetivos propostos. 
Para Santos (2013), dentre os fatores que contribuem para esses sentimentos, está a centralidade da meta no trabalho bancário, visto ser a principal tarefa a ser executada. Atingir a meta é essencial no dia a dia desses trabalhadores, pois ela é extremamente importante para a instituição bancária. Assim, como os bancários pesquisados por Santos (2013), nossos sujeitos da pesquisa vivenciam a angústia ao não atingirem os números, referindo sentirem-se pressionados, desmotivados e intensamente cobrados, de acordo com o relato.

Olha, se eu fosse te dizer como eu me sinto no meu trabalho, eu me sinto cobrada. Cobrada. [...] Eu abriria mão dos meus $16 \%$ de aumento se me dessem $16 \%$ menos de meta.

No que tange ao sentimento de incompetência, Dejours (2007), o relaciona à negação do real. Isso porque, nesses casos, supervaloriza-se o gerenciamento, levando a interpretação dos fracassos no trabalho, como resultantes da incompetência, falta de seriedade, desleixo, despreparo, má vontade, incapacidade ou erro humanos. Assim como no recorte que segue, em que a trabalhadora se empenha, refere sobre a possibilidade da meta estar mal orçada e de que deu o melhor de si, mas mesmo assim, ao não atingir o objetivo proposto, sente-se incompetente.

Pode tá mal orçado, mas tu vai tentar fazer o teu melhor. [...] Claro que é difícil, porque às vezes tu não chega numa meta lá, e tu se sente incompetente. Isso tem. [...] Por isso que eu digo que o banco nos escraviza às vezes, porque tu se sente mal. [...] Então é... E a gente se sente incompetente com essa cobrança diária, tu se sente meio que incompetente. Hoje eu entreguei, amanhã, sei lá, não entrego, tu já se sente mal, já se sente incompetente.

Dejours (2007) afirma que "há os indolentes e os desonestos, mas, em sua maioria, os que trabalham se esforçam por fazer o melhor, pondo nisso muita energia, paixão e investimento pessoal (p. 34)", esperando que de sua contribuição, advenha uma retribuição. Porém, o que se percebe, é que eles querem trabalhar, se empenham, mas se não obtiver o número, não é suficiente. Se por outro lado conseguirem atingir, esse sempre será aumentado, como no comentário a seguir.

Outra questão negativa é essa pressão. É tu trabalhar e tu tá dando o máximo de ti, porque, eu vejo assim, a grande maioria dos colegas tá ali, tá trabalhando, tá fazendo o máximo. Mas, tu nunca, parece que tá sempre, sempre querem mais. Tu atingiu, "ah, mas agora é mais, tu atingiu, mas agora é mais".

Além das frustrações mencionadas, outra fonte de sofrimento relatada pelos bancários diz respeito à sensação de que seu trabalho acaba se perdendo, assemelhando-se aos achados de Santos (2013). No caso do banco onde foi realizado nosso estudo, as metas são 
determinadas semestralmente, porém diariamente e semanalmente, são definidos produtos foco para serem vendidos. Ao mesmo tempo em que os gerentes devem visualizar os objetivos/metas do semestre, diariamente e semanalmente, eles precisam perpetrar esforços adicionais para vender os produtos foco. Acrescentemos a isso o fato de que terminando o dia, a semana ou o semestre, "zera tudo", pois novas metas são definidas. Portanto, como a construção desse profissional ocorre a cada dia, ao alcançar o objetivo, o todo não é visualizado, o trabalho é facilmente esquecido.

Outra questão mencionada pelos trabalhadores é de que não existe um meio-termo, ou seja, se a meta for atingida completamente, nesse caso existirá o reconhecimento. Porém, caso a meta não seja atingida, mesmo que o trabalhador chegue muito perto, isso não será considerado, o esforço despendido para chegar até lá não tem valor algum, pois atingir parcialmente a meta é o mesmo que não atingi-la. Tal fato é corroborado por achados de Barreto e Heloani (2014), os quais referem que, em geral, as empresas não avaliam o esforço empregado para realizar uma tarefa, apenas seu resultado. O que pode levar o trabalhador a não se sentir reconhecido e, consequentemente, levar ao sofrimento.

[...] em relação à cobrança do banco ou tu é zero ou tu é dez. Tu nunca vai dizer assim, bom tu atingiu 95\% das tuas metas, é a mesma coisa que tu não ter atingido nada.

Concordamos com Sznelwar, Uchida e Lancman (2011), quando referem que na contemporaneidade, a supremacia do capital financeiro exige dos sujeitos um crescimento infinito, a fixação de metas insensatas, alicerçados na ideia de homem com ilimitada capacidade de superação, os quais estão adoecendo por conta do trabalho. Isso porque, só é bem-sucedido quem consegue atingir as metas, cada vez mais desafiadoras. Entendemos que a mensagem transmitida aos trabalhadores é que existem dois tipos de sujeitos, os vencedores que atingem as metas, e os perdedores - que não conseguem chegar lá. Essa lógica pode levar os trabalhadores a pensarem que os objetivos devem ser atingidos a qualquer custo, independentemente dos meios utilizados para tal fim.

\section{Sobrecarga de Trabalho e o Sofrimento Ético}

No Brasil, nos anos 1980, surgiu e intensificou-se a reestruturação produtiva, a qual se estende a diversos setores da economia. Foram modificações sociais, políticas e econômicas, que implicaram em privatizações, fusões, além de medidas para incremento dos lucros e 
redução de postos de trabalho (Barreto \& Heloani, 2014). Segnini (1999) destaca que, no caso dos bancos, esse processo ocorreu mais intensamente em meados dos anos 1990, quando se observou a drástica redução tanto do número de bancos no país, quanto de trabalhadores bancários. Como consequência desse cenário, observaram-se o aumento no volume de trabalho, assim como sua intensificação, também a redução dos níveis hierárquicos, além da implementação de programas de reengenharia.

Salientamos ainda que os trabalhadores se encontram duplamente pressionados. De um lado pelos clientes, que anseiam por ter seus problemas resolvidos, e de outro lado, o banco, que impõe o cumprimento das metas, a efetivação dos negócios, bem como, a venda dos produtos. Nesse sentido, é impreterível que os bancários empreendam exaustivo esforço para conseguir atender bem ao cliente e, ao mesmo tempo, conseguir efetuar vendas que os ajudem a atingir os objetivos estipulados. Oltramari e Grisci (2012) acrescentam que, no caso específico dos gerentes intermediários, as demandas a serem atendidas dizem respeito aos clientes, funcionários e superiores. Os entrevistados alegam que atender bem ao cliente, muitas vezes, por conta do volume de trabalho, associado à escassez de funcionários, não é possível, fato que se constitui em fonte de sofrimento.

\begin{abstract}
Agora essa pressão de fazer, que tem que fazer um monte com pouco tempo, com pouca estrutura, pouca gente pra fazer. [...] Então é isso, é trabalhar de uma forma exageradamente, do tipo tu não sabe se tu atende o telefone ou se tu atende o cliente que tá na tua frente, como já aconteceu, que o pessoal ri muito da minha cara, de eu botar a mão no telefone e olhar pro cliente e dizer alô, pro cliente. Porque eu não sabia se eu atendia o cliente ou se eu atendia o telefone. [...] porque eu tava com uma pluralidade de ações pra fazer.
\end{abstract}

No caso do banco pesquisado, ajustes no quadro de trabalhadores decorrentes da extinção de setores mais voltados para o suporte são recorrentes, visto a empresa estar voltada para vendas, sendo o foco no negócio. Isso posto, o comentário verbal que segue denota o sofrimento e a angústia advindos da impossibilidade de concluir o trabalho, de acumular pendências, deparando-se diariamente com uma demanda exaustiva de serviço, sem conseguir "vencê-lo", além da angústia de ter que realizar vendas em meio a toda burocratização da atividade. Estamos diante do fracasso no processo de trabalho, que leva ao sofrimento (Dejours, 2008), este revelando-se pela distância existente entre o que se espera que os trabalhadores realizem durante sua jornada de trabalho e aquilo que efetivamente é possível.

É bastante coisa, o volume de serviço e ainda tu tem que aliar essa parte negocial. É bem complicado assim, nesse ponto. Não tem um dia que tu consiga sair daqui e dizer que conseguiu terminar de fazer tudo que tinha no dia. Nunca, não existe isso. Há 11 anos eu não sei o que é isso. Sempre fica uma coisa pro outro dia. 
Disso depreendemos que a qualidade do trabalho, sobretudo aquele não diretamente ligado à parte negocial fica prejudicado. Fator este que provoca a desestabilização dos valores dos sujeitos, do que se constitui em um trabalho bem feito, sua responsabilidade e ética, levando-o ao sofrimento psíquico, pela impossibilidade de realizar um bom trabalho. Percebemos então, nos comentários verbais emitidos pelos trabalhadores, o mal-estar e o sofrimento, decorrentes da imposição de metas difíceis de serem atingidas, associadas a um quadro enxuto de funcionários e a um volume excessivo de trabalho, seguidamente, levando os sujeitos a realizarem vendas mal feitas, por falta de tempo e, em consequência, de uma boa análise das necessidades do cliente ou pela obrigação de atender aos desígnios da empresa.

O trabalhador se vê diante de um conflito moral e emocional, que ocasiona medo, insegurança, angústia, vergonha. É o sofrimento ético, que conforme Vasconcelos (2013) é experienciado pelo sujeito, quando submetido a situações de trabalho, ou participa destas, e as mesmas são contrárias aos seus valores, logo discorda delas. Ademais, não é capaz de enfrentar e confrontar o que por ele é considerado reprovável, comportando-se de maneira contraditória no que diz respeito às suas convicções morais. Portanto, as falas apresentadas pelos trabalhadores são extremamente expressivas do sofrimento vivenciado pelos mesmos, frente ao dilema do dia a dia deles, que consiste em atender ao cliente em sua demanda e, por outro lado, atender aos objetivos impostos pelo banco, visto implicar a realização do seu trabalho. Ademais, os bancários ficam com a sensação permanente de não conseguir terminar seu trabalho. Encontram-se imersos na angústia decorrente das pressões por metas e excesso de trabalho, ficando vulneráveis ao adoecimento físico e psíquico.

Então muitas vezes pro cliente, tu fica numa linha muito tênue entre tu trabalhar, atender ao banco, ou realmente atender o que o cliente deseja e que seria adequado. Então essa cobrança e ao mesmo tempo o cliente, e tu sentindo a confiança do cliente, tu se sente mal se porventura tu tendeu mais pro banco do que pra o cliente. Aí que gera um mal estar [...].

\section{A Quantofrenia}

A quantofrenia, conforme explicitado por Gaulejac (2007), consiste na tradução sistemática de fenômenos sociais e humanos em números. Baseia-se na crença de que instrumentos de medida são passíveis de serem utilizados para compreender e dominar a realidade, ou seja, de que a objetividade pode ser traduzida em termos matemáticos. $\mathrm{Na}$ instituição pesquisada, isso se traduz pela sensação de que as pessoas não são vistas como 
sujeitos, eles são o número que apresentam, seja no final do semestre, seja nas campanhas que implicam em um esforço de vendas de produtos foco ou no dia a dia.

A gente é um número, em qualquer empresa, no banco não é diferente. Então, eles não vão olhar lá pro meu nome por, ou pra minha cara por me achar bonito ou feio, eles vão olhar, o D. é gerente de uma carteira, e a carteira dele não tá apresentando o resultado esperado.

O conceito de quantofrenia aparece muito ligado ao de qualidade total, está intimamente atrelada à excelência tanto de processos, quanto de produtos. Porém, em consonância com Gaulejac (2007), lembramos que excelência significa superação, é algo fora do comum e não pode ser partilhado. Dentro dessa lógica, busca-se incitar todos os trabalhadores, rumo à contínua superação, em busca "de um ideal mítico inacessível (Gaulejac, 2007, p. 87)"'. Alguns trabalhadores se dão conta disso, dessa impossibilidade de atingir certos objetivos estipulados ou de determinado ideal de excelência e sofrem com isso, mas também se autorresponsabilizam. Isso porque a empresa se apresenta como um objeto de investimento, onde cada indivíduo é convocado a introjetar fortemente os valores institucionais (Gaulejac, 2007), principalmente, os gerentes.

Então as metas e o quadro comparativo, por produtos, entre os colegas é muito, isso aí judia muito da gente. [...] o banco, ele quer que tu atenda bem, que tu venda bem, mas o principal é o número. Não adianta tu atender bem e não ter número. Ele quer os dois. [...]Bom mas tu ter os dois é tu ser um super funcionário. E super funcionário, a gente, todo mundo quer, só que às vezes falta até capacidade pra gente ser isso.

Salientamos que a ideologia gerencialista se encontra tão profundamente difundida e interiorizada pelos trabalhadores na contemporaneidade, que a lógica quantofrênica aparece em alguns de nossos depoimentos como fonte de reconhecimento, transformado em prazer.

[...] sistema de gestão de competências, onde a gente é avaliado semestralmente a respeito do que a gente produz dentro do banco. Eu nunca tive avaliações negativas lá, sempre tive feedbacks positivos. Então, nesse sentido, eu me sinto reconhecido. Eu acho ideal a forma que o banco, dispõe uma ferramenta pra mostrar, ficar lá gravado o fato de tu ter feito teu trabalho corretamente.

Afora termos encontrado vivências de prazer ligadas à quantificação dos resultados, que vão ao encontro de Dejours e Bègue (2010) ao afirmarem que o trabalho propriamente dito é impossível de ser mensurado, logo, tais métodos de avaliação se fundamentam em bases científicas ilegítimas. Sobretudo, porque as instituições bancárias são "assentadas em competências relacionais - o que dificulta a objetivação, tornando praticamente impossível a medida dos recursos psicológicos engajados no trabalho efetivo" (p. 45). Desse modo, 
avaliações quantitativas de desempenho são falsas, além de serem parciais, causando danos à saúde mental do trabalhador.

\section{Adoecimento no Trabalho}

No tocante às situações de adoecimento vividas pelos entrevistados, as quais serão explicitadas nas linhas que seguem, chama a atenção o fato de os entrevistados relatarem situações de adoecimento, fazendo a ligação com o trabalho. Isto porque os trabalhadores em geral, não costumam associar o adoecimento ao trabalho, sobretudo em se tratando de problemas físicos e muitas vezes o adoecimento psíquico também não. Os sintomas referidos dizem respeito tanto ao adoecimento físico quanto psíquico.

Em estudos de Seligmann-Silva (2011), a intensificação dos ritmos de trabalho é considerada fator preponderante ao provocar cansaço e nervosismo. Ademais, atividades que requerem muita concentração e atenção, sobretudo se acumularem grande responsabilidade, levam à forte tensão. Conforme já mencionamos neste trabalho, a intensificação e sobrecarga de trabalho é recorrente nas atividades bancárias, por conta da automatização e redução dos postos de trabalho, que têm como consequência o número cada vez menor de pessoal para realizar uma mesma atividade ou o acúmulo de várias atividades para uma mesma pessoa. Acrescenta-se a isso, o fato de nossos entrevistados ocuparem cargos de gestão intermediária, pois são responsáveis por uma carteira de clientes, sofrendo pressão destes para a resolução de seus problemas, de seus superiores, para o atingimento dos resultados, e ainda dos subordinados, sobretudo por terem que administrar questões de relacionamento interpessoal. Toda essa sobrecarga se transforma em sintomas físicos ou psíquicos, conforme ponderações.

Mas é....é um trabalho que é estressante, bastante estressante. Muitas vezes eu chego em casa cansado, com dor de cabeça. É um trabalho que tu é bastante cobrado.

Nas empresas privadas, os trabalhadores toleram a precarização do trabalho e a injustiça, sobretudo por conta da ameaça de demissão (Dejours, 2007). Já, na instituição estudada, podemos verificar que o medo é outro, está relacionado à perda do cargo ocupado, que traz tantos prejuízos financeiros, visto os gerentes receberem uma comissão (remuneração adicional), como forma de compensar a responsabilidade maior por gerir uma carteira de clientes, além de contar com subordinados. 
Semestralmente, quando há distribuição de lucros pela empresa, esta é proporcional ao salário percebido, logo a participação nos lucros vai crescendo, conforme o cargo ocupado na cadeia hierárquica. Há também o prejuízo simbólico, pela perda do status social, ao deixar de ser gerente. Disso, tem-se que as pessoas que ocupam um cargo comissionado empreendem todo o esforço possível no sentido de mantê-lo, mesmo à custa de sua saúde física ou mental.

Seligmann-Silva (2011) chama a atenção para as limitações impostas pela fadiga ou cansaço, na disposição para a vida fora do trabalho. Em nossa amostra, verificamos que alguns dos trabalhadores buscam formas de driblar essa fadiga, a fim de poder realizar as atividades do dia a dia que extrapolam o âmbito do trabalho, ligadas ao ambiente familiar.

Procuro sempre fazer alguma atividade. Tem épocas, ultimamente tem sido bastante raras, que a gente chega exausto e acaba querendo ficar só em casa. Mas geralmente, eu mesmo chegando exausto, eu tento fazer alguma atividade pra não ficar só em casa.

Por outro lado, há outros que não encontram mais forças para driblar a fadiga e acabam deixando de lado os momentos de lazer, por falta de energia.

Mas normalmente eu saio, já direto, cansada, esgotada. Tinha uma época que eu já saía e dormia direto, e dormia a noite inteira e acordava de manhã cansada.

Em nossos estudos, assim como nos de Seligmann-Silva (2011), os trabalhadores relatam o cansaço que, por sua vez, interfere na qualidade e/ou dificuldade do sono. Sendo que essas dificuldades foram relacionadas a preocupações com o trabalho.

Quando eu entrei no banco, eu era muito estressada, eu me preocupava, eu não dormia pensando no serviço, pensando nas metas, eu contava os dias para entrar em férias, pra chegarfinal de semana.

Ainda, referindo-nos aos achados de Seligmann-Silva (2011), temos que nestes, assim como no nosso, os distúrbios psicossomáticos relacionados a situações laborais foram bastante frequentes e divergentes. Bem como alguns outros quadros relacionados à psicopatologia, às depressões também foram largamente manifestas, conforme segue:

Então pra mim foi difícil. Eu quase fiquei doente, pela preocupação de trabalhar, de fazer as coisas direito. Quase me deu uma gastrite.

É um trabalho maçante, estressante, sobrecarregado e sem reconhecimento. [...]Tanto que o índice de stress hoje da empresa está muito mais alto. [...] Até aonde o pessoal vai aguentar essa sobrecarga, até aonde vai aguentar as coisas. 
A preocupação é maior, ao lembrarmos que muitos casos de adoecimento não são notificados, especialmente os relacionados a episódios depressivos, visto serem alvo de preconceito. O adoecimento é iminente, conforme dados disponíveis e o sofrimento verbalizado.

Então, na minha (agência), hoje, quando eu acordo, é mais um dia que eu tenho que trabalhar esperando chegaro final de semana, pra poder viver.

Concordamos com Gaulejac (2007), quando ele afirma que "as doenças profissionais e os acidentes de trabalho são um sintoma da dureza das condições de trabalho" (p. 207), que pode ser ratificado pelo enunciado a seguir:

E o que a gente vê é uma competição em um nível estratosférico dos bancos, cada um querendo ter o maior lucro, e o funcionalismo adoecido, adoecendo e abandonado.

\section{CONSIDERAÇÕES FINAIS}

A pesquisa desenvolvida, a qual teve seus resultados parcialmente apresentados neste artigo, tinha como objetivo indireto efetuar uma discussão acerca do trabalho contemporâneo, das relações de trabalho e das repercussões destes na saúde do trabalhador bancário. Isso, porque acreditamos no papel fundamental do trabalho na construção e afirmação da identidade dos sujeitos, bem como de seu potencial em ser fonte de prazer, na medida em que é possível a utilização da criatividade ou de sofrimento, caso não haja espaço para essa. Acreditamos, assim como a Psicodinâmica do Trabalho, que um espaço de escuta para os trabalhadores é absolutamente necessário, no intuito de fortalecer, ou caso oportuno, criar laços de confiança, permitindo repensar o espaço laboral e ressignificar o sofrimento. Sobretudo, nessa categoria da gerência intermediária, vista a maior competitividade, devido ao nível hierárquico e, em consequência, o maior individualismo.

Ao analisar a dinâmica prazer-sofrimento no trabalho desses bancários, observamos, no que diz respeito às vivências de prazer, que estas se encontram ligadas à satisfação em solucionar problemas dos clientes, ao contentamento em ser útil, além do reconhecimento proporcionado ao sentirem-se capazes de resolver problemas, o que adicionalmente confere sentido ao trabalho do bancário.

Relativamente às fontes de sofrimento, a cobrança excessiva de metas consideradas inatingíveis, juntamente com o progressivo aumento destas, intensificam sentimentos de incompetência e menos-valia. Esse contexto é acentuado pelas avaliações individuais de desempenho e pela inexistência de um instrumento de avaliação que meça o esforço empregado 
para realização da tarefa, ou seja, apenas o resultado obtido conta. Nesse ponto, emergem o dinamismo e o caráter subjetivo de nossas vivências, pois, ao mesmo tempo em que o reconhecimento funciona como fonte de prazer ao atingir a meta, pode provocar sofrimento, no longo prazo, pela frustração de não alcançar os objetivos propostos pela instituição. $O$ volume excessivo de serviço também é mencionado como causador de desconforto, causando impotência e incompetência pela impossibilidade de realizar um trabalho bem feito. Tais achados corroboram estudos de Netz e Amazarray (2005), Netz e Mendes (2006) e Jacques e Amazarray (2006).

Além desses, o sofrimento ético também foi visibilizado na forma de sofrimento, visto o comprometimento do trabalhador com a instituição, que deseja ao mesmo tempo atender aos objetivos propostos e às necessidades dos clientes, muitas vezes, existindo uma distância entre esses interesses, a qual pode ocasionar doenças relacionadas ao trabalho. Aliás, vários sintomas, tanto de adoecimento físico, quanto psíquico, foram mencionados por nossos entrevistados. Por fim, a sensação de estabilidade e quantofrenia, assim como o reconhecimento já mencionado, foram percebidos ora como fontes de sofrimento, ora como fontes de prazer.

Inferimos que, ao nos propormos discutir as relações de trabalho contemporâneas e suas repercussões na saúde do trabalhador, mesmo não sendo possível viabilizar um coletivo de discussão, conforme preconizado pela PdT, oportunizamos um espaço que possibilitou a escuta dos trabalhadores e, a partir dessa escuta, foi favorecido a eles escutar a si mesmo e pensar sobre o seu trabalho. Sendo assim, acreditamos ter ensejado a reflexão.

\section{Referências}

Aguiar, V. B. (2013). Psicodinâmica da relação gestor-equipe: análise do prazer-sofrimento no trabalho em uma organização pública. Dissertação de Mestrado, Universidade de Brasîlia, Brasîlia, DF, Brasil.

Alliez, E., \& Feher, M. (1988). Os Estilhaços do Capital. In: E. Alliez, M. Feher, D. Gille, \& I. Stengers. (Org.). Contratempo: ensaios sobre algumas metamorfoses do capita. (p. 149-214). Rio de Janeiro: Forense Universitária.

Antunes, R. (1999). Os sentidos do trabalho: ensaio sobre a afirmação e a negação do trabalho. 6 $6^{\text {a }}$ ed. São Paulo: Cortez; Campinas/SP: UNICAMP, 1999.

Antunes, R. (2002). Adeus ao trabalho? Ensaio sobre as metamorfoses e a centralidade do mundo do trabalho (6a ed.). São Paulo/SP: Boitempo.

Barreto, M., \& Heloani, R. (2014). Assédio moral como instrumento de gerenciamento. In: A. R. C. Merlo, C. G. Bottega, \& K. V. Perez. (Org.). Atenção à saúde mental do 
trabalhador: sofrimento e transtornos psíquicos relacionados ao trabalho (p. 30-51). Porto Alegre: Evangraf.

Breakwell, G. M., Fife-Schaw, C., Hammond, S., \& Smith, J. A. (2010). Métodos de pesquisa em psicologia. Porto Alegre: ARTMED.

Cardoso, M. R. (2001). Christophe Déjours. Ágora: Estudos em Teoria Psicanalítica, 4 (2), 89-94.https://dx.doi.org/10.1590/S1516-14982001000200007.

Castel, R. (1998). As metamorfoses da questão social: uma crônica do salário. Trad. Iraci D. Poleti. Petrópolis, RJ: Vozes.

Cruz, O., Neto. (2002). O trabalho de campo como descoberta e criação. In: S. F. Deslandes, O. Cruz, O., Neto, R. Gomes, \& M. C. S. Minayo. Pesquisa Social: teoria, método e criatividade (21a ed., PP 9-29). Petrópolis, RJ: Vozes.

Decca, E. S. de. (1996). O nascimento das fábricas. São Paulo: Editora Brasiliense.

Dejours, C. (2004). Subjetividade, trabalho e ação. Produção, 14 (3), 27-34. https $/ /$ dx.doi.org/10.1590/S0103-65132004000300004.

Dejours, C. (2004a). A Metodologia em Psicopatologia do Trabalho. In: S. Lancman, \& L. I. Sznelwar. Christophe Dejours - Da Psicopatologia à Psicodinâmica do Trabalho (pp. 105-126). Rio de Janeiro: Ed. Fiocruz/ Brasilia: Paralelo 15.

Dejours, C. (2005). O fator humano. (5a ed., M. I. S. Betiol \& M. J. Tonelli, Trad.). Rio de Janeiro: Editora FGV.

Dejours, C. (2007). A banalização da injustiça social. (7a ed., 8a reimpr., L. A. M.). Rio de Janeiro: Editora FGV.

Dejours, C. (2008). Trabalho, tecnologia e organização: avaliação do trabalho submetida à prova do real. In: L. I. Sznelwar \& F. L. Mascia (Org.) Cadernos de TTO, no 2. São Paulo: Blucher.

Dejours, C. (2009). Trabalho e saúde mental: da pesquisa à ação. 1989 In: C. Dejours, E. Abdoucheli, \& C. Jayet. (Org). Psicodinâmica do trabalho: contribuições da escola dejouriana à análise da relação prazer, sofrimento e trabalho. (1a ed., 10a reimpr., pp.45-65). São Paulo: Atlas. (Original published in 1993).

Dejours, C. \& Adboucheli, E. (2009). Trabalho e saúde mental: da pesquisa à ação. 1990 In: C. Dejours, E. Abdoucheli, \& C. Jayet. (Org). Psicodinâmica do trabalho: contribuições da escola dejouriana à análise da relação prazer, sofrimento e trabalho. (1a ed., 10a reimpr., pp.119-145). São Paulo: Atlas. (Original published in 1993).

Dejours, C., \& Bègue, F. (2010). Suicídio e trabalho: o que fazer. (F. Soudant, Trad.) Brasilia: Paralelo 15, 2010.

Dejours, C., \& Mello, G. A. R., Neto (2012). Psicodinâmica do trabalho e teoria da sedução. Psicologia em Estudo, 17(3), 363-371. https://dx.doi.org/10.1590/S141373722012000300002. 
Gaulejac, V. de. (2007). Gestão como doença social: ideologia, poder gerencialista e fragmentação social (I. Storniolo, Trad.). Aparecida/SP: Ideias \& Letras.

Gernet, I., \& Dejours, C. (2011). Avaliação do trabalho e reconhecimento. In: P. F. Bendassoli, \&, L. A. P. Soboll. (Org.). Clínicas do trabalho: novas perspectivas para compreensão do trabalho na atualidade (pp. 61-70). São Paulo: Atlas.

Grisci, C. L. I., Scalco, P. D., \& Kruter, G. E. (2011). Dilemas pessoais no trabalho imaterial bancário. Psicologia \& Sociedade, 23(3), 564-573.

Guimarães, S. M. (2006). Fordismo e pós-fordismo. In: Cattani, A. D. \& Holzmann, L. (Orgs.) Dicionário de trabalho e tecnologia (pp. 133- 136). Porto Alegre: Ed. da UFRGS.

Heloani, R., \& Lancman, S. (2004). Psicodinâmica do trabalho: o método clínico de intervenção e investigação. Production, 14(3), 77-86. https://dx.doi.org/10.1590/S0103$\underline{65132004000300009}$.

Jacques, M. da G. C., \& Amazarray, M. R. (2006). Trabalho bancário e saúde mental no paradigma da excelência. Boletim da Saúde, 20 (1), 93-105. Retrieved March 04, 2018, from:

http://www.medtrab.ufpr.br/arquivos\%20para\%20download/saude_mental/TRABALHO \%20BANC\%C1RIO \%20E\%20SA\%DADE\%20MENTAL\%20NO\%20PARADIGMA $\% 2$ 0DA\%20EXCEL\%CANCIA.pdf.

Merlo, A. R. C. (2000). Transformações no mundo do trabalho e a saúde. In: Associação Psicanalítica de Porto Alegre. O valor simbólico do trabalho e o sujeito contemporâneo (pp. 271-278). Porto Alegre: Artes e Ofícios.

Nardi, H. (2006). Trabalho, Subjetividade e Ética: os processos de subjetivação de duas gerações de trabalhadores metalúrgicos e do setor informal (1970-1999). Porto Alegre: Editora da UFRGS.

Netz, J. A., \& Amazarray, M. R. (2005). A organização dos trabalhadores na resistência às práticas discriminatórias: um olhar acerca da subjetividade, saúde e trabalho. Revista Virtual Textos \& Contextos, 4, ano IV, 1-16. Retrieved March 04, 2018, from http://revistaseletronicas.pucrs.br/fzva/ojs/index.php/fass/article/view/1003/783

Netz, J. A., \& Mendes, J. M. R. (2006). O massacre dos trabalhadores bancários e a ação sindical: sobrejornadas, metas excessivas, pressão, medo, práticas gerenciais autoritárias versus práticas preventivas. Boletim da Saúde, 20 (1), 25-34. Retrieved March 04, 2018, from http://www.boletimdasaude.rs.gov.br/conteudo/1352/0-massacre-dos-trabalhadoresbancarios-e-a-acao-sindical:-sobre-jornadas,-metas-excessivas,-pressao,-medo,-praticasgerenciais-autoritarias- versus-praticas-preventivas.

Oltramari, A. P., \& Grisci, C. L. I. (2012). Trajetórias, Dilemas e Transições nas Carreiras de Executivos Bancários. Revista Gestão \& Tecnologia, 12 (1), 126-150. Retrieved March 04, 2018 , from:

http:/gvpesquisa.fgv.br/sites/gvpesquisa.fgv.br/files/arquivos/andrea_poleto_oltramari_tr ajetorias_e transicoes_nas_carreiras_de_executivos.pdf.

Perez, K. V. (2012). "Se eu tirar o trabalho, sobra um cantinho que a gente foi deixando ali”: clínica da Psicodinâmica do Trabalho na atividade de docentes do ensino superior 
privado. Dissertação de Mestrado, Universidade Federal do Rio Grande do Sul, Porto Alegre, RS, Brasil.

Resende, S. (2003). Valores individuais e vivências de Prazer e Sofrimento em bancários de instituições públicas e privadas. Dissertação de Mestrado, Universidade de Brasîlia, Brasîlia, DF, 2003.

Resende, S., \& Mendes, A. M. (2004). A sobrevivência como estratégia para suportar o sofrimento no trabalho bancário. Rev. Psicol., Organ. Trab., 4 (1), 151-175. Retrieved March 2018,

http://pepsic.bvsalud.org/scielo.php?script=sci_arttext\&pid=S1984$\underline{66572004000100007 \& \operatorname{lng}=p t \& n r m=\text { iso. }}$.

Santos, C. L. S. dos. (2013). Trabalho bancário em tempos de sofrimento psíquico: metas e sobrevivência. Dissertação de Mestrado, Universidade Federal do Rio Grande do Sul, Porto Alegre, RS, Brasil.

Segnini, L. R. P. (1999). Reestruturação nos bancos no Brasil: desemprego, subcontratação e intensificação do trabalho. Educação \& Sociedade, 20 (67), 183-209. https:/dx.doi.org/10.1590/S0101-73301999000200007.

Seligmann-Silva, E. (2011). Trabalho e desgaste mental: o direito de ser dono de si mesmo. (1a ed., 1a reimpr.). São Paulo: Cortez.

Silveira, D. T., \& Córdova, F. P. (2009). A pesquisa científica. In: T. E. Gerhardt, \& D. T. Silveira. (Org). Métodos de Pesquisa. (pp. 31-42). Porto Alegre: Editora da UFRGS.

Sznelwar, L. I., Uchida, S., \& Lancman, S. (2011). A subjetividade no trabalho em questão. Tempo Social: Revista de Sociologia da USP, 23 (1), pp. 11-30. Retrieved March 04, 2018, from: http $/ /$ www.scielo.br/pdf/ts/v23n1/v23n1a02.

Vasconcelos, A. C. L. (2013). Sofrimento Ético. In: F. O. Vieira, A. M. Mendes, \& A. R. C. Merlo. (Org). Dicionário crítico de gestão e psicodinâmica do trabalho (pp. 421-425). Curitiba: Juruá. 